\title{
Erratum to: Geochemical characteristics of Ordo- vician crude oils in the northwest of the Tahe oil field, Tarim basin
}

\author{
YU Qiuhua ${ }^{1,2,3^{*}}$, WEN Zhigang ${ }^{2,3}$, TANG Youjun ${ }^{2,3}$, and PANG Xiongqi ${ }^{1}$ \\ ${ }^{1}$ Basin \& Reservoir Research Center, China University of Petroleum, Beijing 102249, China \\ ${ }^{2}$ Key Laboratory of Exploration Technologies for Oil and Gas Resources; Ministry of Education; Jingzhou 434023, China \\ ${ }^{3}$ Department of Geochemistry, University of Yangtze, Jingzhou 434023, China \\ *Corresponding author, E-mail: yuqiuhua@126.com
}

Received July 20, 2009; accepted August 25, 2009

(C) Science Press and Institute of Geochemistry, CAS and Springer-Verlag Berlin Heidelberg 2011

Erratum to: Chin.J.Geochem.(2011)30:093-098

DOI: $10.1007 / \mathbf{s 1 1 6 3 1 - 0 1 1 - 0 4 8 9 - 3}$

In the online version of the article, the fourth author, PANG Xiongqi, is missing.

The online version of the original article can be found at

http://dx.doi.org/10.1007/s11631-011-0489-3 